CATALAN REVIEW

Catalan Review

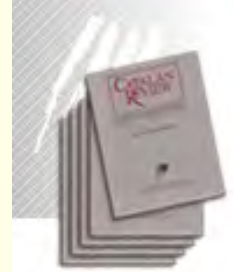

You are accessing the Digital Archive of the Catalan Review Journal.

By accessing and/or using this Digital Archive, you accept and agree to abide by the Terms and Conditions of Use available at http://www.nacs-

catalanstudies.org/catalan review.html

Catalan Review is the premier international scholarly journal devoted to all aspects of Catalan culture. By Catalan culture is understood all manifestations of intellectual and artistic life produced in the Catalan language or in the geographical areas where Catalan is spoken. Catalan Review has been in publication since 1986 .
NORTH

AMERICAN

CATALAN

SOCIETY
Esteu accedint a l'Arxiu Digital del Catalan Review

A l' accedir i / o utilitzar aquest Arxiu Digital, vostè accepta i es compromet a complir els termes i condicions d'ús disponibles a http://www.nacs-

catalanstudies.org/catalan review.html

Catalan Review és la primera revista internacional dedicada a tots els aspectes de la cultura catalana. Per la cultura catalana s'entén totes les manifestacions de la vida intel lectual i artística produïda en llengua catalana o en les zones geogràfiques on es parla català. Catalan Review es publica des de 1986.

\title{
Al caliu de la Rosa de Foc: Apropiacions insolents de l'espai públic a Barcelona (1996-2004) Manuel Delgado
}

Catalan Review, Vol. XVIII, number 1-2, (1998), p. 41-66 


\section{AL CALIU DE LA ROSA DE FOC: APROPIACIONS INSOLENTS DE L'ESPAI PÚBLIC A BARCELONA (1996-2004)*}

MANUEL DELGADO

\section{ABSTRACT}

In contrast to the triumphant vision of Barcelona as a center of design, fashion, and tourism, the city that Manuel Delgado explores is one that is profoundly marked by the power of the street and popular movements. Drawing on collective ethnographic research on public space, Delgado considers the ties and tensions between urbanism and urbanity; the city as planned by politicians, engineers, architects, and designers and the city as practiced by its inhabitants and visitors; official monumentalizations and popular mobilizations. After an overview of the uses of the street in the late nineteenth and early twentieth centuries (ranging from religious processions to revolutionary barricades), the focus shifts to anti-militarist, anti-capitalist, and pro-okupa demonstrations in the late twentieth and early twenty-first centuries.

\section{LA VELLA CIUTAT DESOBEDIENT}

Més enllà dels projectes urbanístics, la urbanitat - aquesta forma de vida social feta d'encontres entre desconeguts- és una altra cosa. Per urbanitat s'entén aquí la societat que produeixen els ciutadans i que pot ser contemplada fent-se i desfent-se constantment als carrers i les places, la manera que aquests ciutadans tenen de gastar els espais que al mateix temps utilitzen i generen. Són els practicants de la ciutat els qui constantment es desentenen de les directrius dissenyades, rellegeixen de forma sempre original $\mathrm{i}$ irrepetible els principis arquitectonics que han orientat la morfologia urbana i s'abandonen a modalitats de territorialització efímeres, transversals, sovint furtives. Són ells, els transeünts, els qui creen un univers polièdric, fet de moviments que poden ser

: Aquest article es basa en la recerca Carrer, festa i revolta. Els usos simbòlics de l'espai públic a Barcelona (1951-2000), desenvolupar pel Grup de Recerca Etnografia dels Espais Públics de l'Institut Català d'Antropologia i destinat a l'Inventari del Patrimoni Etnològic de Catalunya. Va comptar amb el suport del Centre de Promoció de la Cultura Popular i Tradicional Catalana, Departament de Cultura de la Generalitat de Catalunya, Els menbres de l'equip investigador van ser: Manuel Delgado (coordinador), Gerard Horta, Andrés Antebi, José Luis Carol, Nadja Monnet, Joan Mayans, Esther Fuster i Sandra Ezquerra. Les fotografies són de Mireia Comas. 
sovint espasmòdics, ja sigui a nivell molecular o massiu. A la ciutat planificada s'hi oposa - o li resta indiferent- la ciutat practicada, tot allò que s'agita al seu si, el que es mou i no es pot aturar, perquè és un pur dinamisme, un ordre mai ordenat del tot, inacabable, un ordit de situacions i d'estructures provisionals, un sistema que tremola. És la Barcelona que no trobarem mai ni a les guies turístiques ni als prospectes de promoció municipal; ni als plànols dels arquitectes ni als plans dels polítics: la Barcelona que es nodreix del mateix que la trasbalsa.

Aquests desmentiments del projecte d'una ciutat transparent i previsible poden venir ocasionats per les apropiacions microscòpiques d'usuaris que, en massa però individualment o en petits grups, la practiquen a la seva manera $i$ al marge de les instruccions d'ús rebudes i de les formes imposades pels polítics i els planificadors. Al mateix temps, els modelatges urbanístics que busquen generar una ciutat-logotip poden ser també desacatades per apropiacions collectives de l'espai urbà a càrrec de sobtades fusions de vianants, cuallargs compactes de ciutadans que decideixen no contribuir a la conversió de Barcelona en un colossal plató televisiu on s'està gravant un ininterromput i enorme espot publicitari. Es tracta, en aquest cas, de l'entrada en escena d'aquest vell protagonista de la vida urbana contemporània al qual massa precipitadament s'havia donat per mort i que no és altre que la multitud, actuant no com a ramat sinó com a llopada.

A la capital de Catalunya, la situació actual presenta un cert paral·lel amb la que dibuixava Temma Kaplan en una obra ja clàssica a propòsit de la manera com les processons religioses, les festes patrocinades per l'Ajuntament i les marxes civils a la Barcelona de finals del XIX i principis del XX llegien i practicaven la trama urbana, fent-ho de manera polèmica, litigant a propòsit de què significava. La gran lliçó de l'obra de Kaplan és que a les ocupacions massives de l'espai públic, tipificades com a manifestacions civils en les quals s'expliciten reclamacions o s'emeten protestes relacionades amb esdeveniments no repetitius, es podrien aplicar els esquemes interpretatius que serveixen per a les anàlisis d'altres transformacions rituals que manipulen simbòlicament els mateixos elements del paisatge i els fan esdevenir significatius. Kaplan ens proposa tot un exhaustiu seguiment de la gramàtica topogràfica que manipulaven les deambulacions rituals per Barcelona a partir de la pèrdua d'importància gradual de les processons de Corpus al llarg del segle XIX. L'obra de Kaplan versa justament sobre com es desplaçaven les grans marxes públiques - religioses, civils, polítiques i sindicals - pel centre de Barcelona, des de 1808 fins a 1936; com les processons en honor de la Mare de Déu de la Mercè baixaven per la Rambla i utilitzaven l'actual carrer Ample fins a la basílica de Santa Maria del Mar; com la històrica manifestació de treballadors del 9 de juliol de 1855 , encapçalada per la pancarta "Associació o Mort", feia un 
itinerari no gaire distint; com la demostració del Primer de Maig de I890 operà un gran circuit que incloïa la Rambla, el Passeig de Colom, el Pla de Palau, el Passeig de Sant Joan, la Plaça de Tetuan, la Gran Via $i$ la Plaça de Catalunya; com les demostracions de dones treballadores de 1913 i 1918 i els funerals per les víctimes d'atemptats anarquistes de 1905 i 1920 utilitzaren també la Rambla; i com tot això no es podia entendre sinó en el context de les grans mobilitzacions populars que agitaren la capital catalana. És així que, per exemple, els intents d'usar el carrer per part de l'Ajuntament, la burgesia i les autoritats religioses amb finalitats legitimadores, inventant les celebracions patronals de la Mercè al setembre de 1902, sols poden ser entesos com una resposta a l'evidència de fins a quin punt les classes populars havien reclamat i obtingut el control sobre l'espai urbà durant la gran vaga general que havia conegut la ciutat el febrer d'aquell mateix any.

Remarcar aquests precedents - els de les manipulacions enfrontades de la xarxa de carrers i places de Barcelona per finalitats proclamatives- ens permet tenir present fins a quin punt la situació no és nova. Constitueix, de fet, el darrer episodi d'una reforma inacabada de Barcelona que va iniciar la burgesia com a nova classe dominant des de la primera meitat del segle XIX. Actualment estem veient la continuació natural, en clau postmoderna, de la reforma urbana impulsada pel primer liberalisme burgès del xIX, mitjançant la qual es va intentar acabar amb l'activitat de les "classes perilloses" i amb les grans lluites socials i obreres a les ciutats, una reforma el paradigma de la qual seria la de París a cărrec del baró Haussmann a mitjan segle. A Barcelona, aquest projecte de domesticació de la ciutat s'iniciarà amb l'obertura de l'eix transversal Ferran-Sant Jaume-Princesa al 1826 i amb la instal-lació degudament subratllada al casc antic dels principals edificis institucionals i una primera entrega de la "recuperació" del front marítim - el Passeig de la Muralla Litoral, la Plaça del Duc de Medinaceli, el Portal de la Pau- i culminarà amb l'Eixample de Cerdà i, ja a principis del segle $\mathrm{xx}$, amb el pla Jaussely i el traçat de la Via Laietana. Les reformes que pretenien desarborar les estructures urbanes en laberint no sols van traçar grans eixos, sinó que a més van instaurar la il-luminació nocturna i van destruir allò que aleshores es va anomenar "illots malsans", al mateix temps que es duien a terme els primers macrocensos per establir amb exactitud la composició social de la població. Aquesta tasca de sotmetiment de l'urbs posava bona cura en les dimensions simbòliques i perceptuals que permetrien fer de la ciutat una realitat social uniformitzada i respectuosa, tal i com va passar amb les intervencions destinades a generar punts simbòlics forts -edificacions, monuments, commemoracions, noms- a partir de la municipalització de les polítiques de monumentalització i memòria que l'Església havia monopolitzat fins aleshores (Michonneau). S'hauria de 
parlar també dels grans esdeveniments - les Exposicions Universals de 1888 i 1929 - justificadors de la modernització de Barcelona, modernització entesa com a homogeneització cultural i subjugació als requeriments urbanístics del desenvolupament capitalista.

La consciència d'aquests precedents és el que explica l'atenció demostrada pels dissenyadors urbans barcelonins actuals a les relacions entre identitat $\mathrm{i}$ arquitectura a Barcelona i a Catalunya: la utopia de Cerdà, el Modernisme i el Noucentisme, és a dir el seguit d'assajos de formalització estètica i ideològica que havia conegur Barcelona en el període que s'estén entre les Exposicions Universals de 1888 i 1929; aquella etapa en què la capital catalana va fer-se digna de denominacions com ara "París del Sud" o "Ciutat dels Prodigis". Va ser aquella dilatada fase la que va fer de Barcelona l'escenari del Gran Somni, el laboratori d'un macroexperiment de modernització sota la direcció de la burgesia. A l'altra cara de la moneda, desentenent-se o mostrant-se hostil als designis oficials sobre el seu destí, hi havia les classes populars de Barcelona, els moviments socials transformadors i inconformistes que es negaven a obeir i que, amb la seva crònica tendència a l'aldarull i la revolta, convertien la ciutat en la Rosa de Foc, aquella ciutat de la qual Engels podia escriure, el 1873 , que era "el centre fabril més important d'Espanya que reuneix a la seva història més lluites de barricades que qualsevol altra ciutat del món" (Engels 198; per a tot aquest període, vegeu Romero-Maura i les aportacions certament notables d'Horta).

De la mateixa manera que la invenció de les festes de la Mercè al 1902 no es pot separar de la vaga general que la precedi mesos abans, tampoc hauriem de perdre de vista, com ens ha fet notar Pere López Sánchez des de la geografia política, fins a quin punt l'obertura de la Via Laietana el juny de 1909 - un dels grans projectes haussmanians que havien d" esponjar" els conflictius barris vells de Barcelona-va tenir una resposta en la gran revolta popular de juliol d'aquell mateix any, la coneguda amb el nom de "Sermana Tràgica" pels seus detractors i amb els de "Setmana Gloriosa" o "Setmana Roja" pels seus actors. Durant aquells dies d'estiu, els carrers de la ciutat van ser testimonis i protagonistes d'un enfrontament entre les institucions de l'Estat i els sectors socials minoritaris que aquest defensa, d'una ban$\mathrm{da}$, i la majoria proletària de la ciutat, de l'altra. Aquest xoc es va produir en forma d'una maniobra policíaca i militar de desobturació, és a dir d'alliberament dels obstacles que barraven la circulació dels seus agents de força: en aquest cas les barricades, aquestes formes d'enginyeria efímera tan intimament lligada a la història de les insurreccions urbanes. Una violenta competència pel control del territori urbà va resoldre's amb la victòria del poder estatal -i dels segments socials minoritaris en nom dels quals actuava- sobre un ampli sector de la 
població que havia aconseguit per uns moments fer-se amb el domini total del seu propi espai de vida. Per mitjà d'un desembossamenti d'un drenatge, una ciutat ocupada durant uns dies pels seus usuaris retornava sota el control dels qui s'hi presentaven com a propietaris. Però el que cal remarcar és que aquesta operació de desembossat no feia sinó confirmar, per la via de la violència policíaca i militar, l'acció executada en el pla urbanístic pel Pla Jaussely i el Pla Baixeres, que consagraven la il.lusió politicourbanística d'una Barcelona transparent i dòcil. Violant aquesta expectativa, desacatant-la frontalment, una munió de ciutadans no amistosos respecte del poder establert va ser capaç de convertir la metròpoli en un embrollament esquerp, fortalesa d'una societat que, de sobte, havia esdevingut hostil i sorda enfront del discurs polític.

Es també d'aquella etapa d'esplendor de la que en certa mesura $s$ 'ha pretès fer reedició a la Barcelona de les darreries del segle XX $\mathrm{i}$ inicis del XXI, però ara en clau d'un procés que ja no és de modernització, sinó de postmodernització. Fora d'aquesta singularitat (que no fa sinó emfasitzar el paper del simulacre i la fragmentació en les polítiques d'homogeneització i legitimació simbòlica), el quadre actual s'assembla notablement al que conegué la Barcelona de fa un segle, inici d'un periode del qual el franquisme no ha estat un parèntesi, sinó una continuació natural. De nou, com abans, com sempre, el disseny urbà assumeix la tasca de generar un escenari predisposat a inspirar, orientar i emmarcar les produccions d'identitat ciutadanes; la festivalització controlada del passat; una arquitectura cada cop més centrada a produir efectes teatrals, on l'ús funcional dels materials és sacrificat per les exigències de l'aparença; l'ús a gran escala de l'ostentació i l'aparatositat festives - les Olimpíades, el Fòrum - com a eixos de la representació del poder polític i l'acatament del poble; el desplegament de mecanismes retòrics que aspiren a una organicitat patrocinada pels seus beneficiaris econòmics; la petulància de les macroinstal-lacions culturals, lúdiques o esportives, confiades a arquitectes i dissenyadors de moda. La fíta és obtenir una ciutat axial, amable i ordenada, però sobrètot espectacular, capaç d'ocultar sota la catifa les misèries i desigualtats de la ciutat real. Ara bé, ara, com aleshores, com sempre, aquests objectius i aquestes polítiques destinades a assolir-ho -èmfasi en el monumental; ideologització de l'espai; esquivament de tota problemàtica social; tractament de l'arquitectura com a teatre destinat a impressionar - es troben cara a cara amb l'inquiet i l'inquietant de la ciutat, moviments socials que fan un ús intens però indisciplinat de l'espai ciutadà com a teatre per al conflicte, els calius encara encesos de la Rosa de Foc. 


\section{ESPAI PÚBLIC I DISSIDÉNCIA COL·LECTIVA}

A l'igual que va passar amb les primeres grans reformes esventradores destinades a pacificar Barcelona no sols per la via policíaca o militar sinó sobretot per la via urbanística, ens trobem ara amb un contrast similar, guardant totes les distàncies que es vulguin entre el context de la Barcelona revolucionària que descrigué Kaplan i l'actual. D’una banda, ens trobem amb les mateixes polítiques de planificació i modelatge de la morfologia urbana que busquen una monitorització radical de les pràctiques socials i l'expulsió definitiva de tot factor intranquil-litzador pels projectes de reapropiació capitalista de la ciutat. De l'altra, ens trobem amb un reviscolament de la vella tradició insubmisa de la ciutat, concretada en sistemàtics apoderaments insolents de l'espai públic per fer visibles voluntats transformadores o de crítica radical. Torna a veure's frustrat avui l'objectiu polític i arquitectònic d'una ciutat plenament assossegada, incapaç d'imposar-se - si més no del tot- a la trama intricada $\mathrm{i}$ interminable d'unes apropiacions públiques de l'espai públic que tendeixen a ser, per definició, indeterminades $\mathrm{i}$ indeterminables. Es una evidència que els desitjos oficials de generar una metròpoli ensinistrada, plegada a les polítiques de promoció que pretenien fer d'ella un decorat passiu, han fracassat en bona mesura. En efecte, a cavall entre el segle XX i el XXI, van produir-se esdeveniments que advertien que, a Barcelona, continuava vigent la percepció polèmica de l'espai públic per part de les autoritats de torn, la seva naturalesa de marc per a una convivència sovint convulsa, ben allunyada del somni d'arquitecturització generalitzada d'escenaris urbans que desitjarien buits, sense usuaris, sense problemes, a disposició d'una especulació que sembla sols formal, però que és també - bé ho sabemeconòmica i servil al control polític.

Els carrers i les places de Barcelona han vist reiteradament reconeguda la seva naturalesa significativa, en el sentit que, més enllà de la seva condició de mers canals per on s'agiten els aspectes més inconstants de la vida urbana quotidiana, podien esdevenir els elements moleculars per a una gramàtica feta de llocs i itineraris, punts, línies i cruilles que eren reclamats com a eloqüents per certes retòriques col-lectives (cf. Delgado). En els darrers anys, en efecte, s'han produït fets a Barcelona que han posat de manifest una avaluació certament singular del que era i havia de ser una apropiació de la seva trama viària per a utilitzacions no ordinàries, derivades del valor simbòlic afegit a la complexa xarxa de funcionalitats assignades a l'espai públic d'una gran ciutat. Es tornaven a reproduir episodis que advertien de la condició crònicament litigada de l'espai públic a Barcelona - de qui és, perquè serveix, quê significa-, la cobdícia per apropiar-se'n i ferho des de criteris de legitimitat i deslegitimitat que no podien ser sinó 
històrics i col-lectius, és a dir provinents d'una memòria compartida en la qual el terra que es trepitja està marcat per tota mena de petjades i marques, com si una cartografia simbòlica que els vianants poden llegir se superposés, com una transparència, a aquella altra on en principi sembla no haver-hi altra cosa que un esquema abstracte $i$ inalterable de traços i cruilles amb nom.

Des del violent desallotjament de l'edifici de l'antic cinema Princesa a la Via Laietana, l'octubre de 1996 , els moviments de dissidència radical no han deixat d'emfasitzar aquest contenciós relatiu als usos i als sentits de l'espai públic. Per descomptat que el moviment okupa era present a la ciutat des de mitjans de la dècada anterior, però va ésser l'assalt policíac contra l'antic cinema, la matinada del 29 , el que podria assenyalar el final ja irreversible de la illusió de les autoritats d'un espai públic barceloni plenament desactivat. Aquella mateixa nit, centenars de joves es manifestaven davant la Prefectura de policia de la Via Laietana per demanar la llibertat dels 48 detinguts, sotmetent-la a un autèntic setge que va obligar al cos de guàrdia a refugiar-se al seu interior. Durant diverses hores, els enfrontaments violents es van estendre per bona part de Ciutat Vella, amb grans estralls en vehicles de la policia, mobiliari urbà i establiments bancaris. La rabiosa resposta dels sectors socials ofesos per l'actuació governativa posava sobtadament de manifest fins quin punt el carrer ja no seria l'aliat submís amb què podrien comptar les autoritats polítiques a Barcelona.

Des d'aquest moment clau que estem ubicant en el desallorjament del cinema Princesa — punt de partida d'un protagonisme creixent de moviments socials no institucionalitzats - s'anirà enregistrant una creixent revisió de les pistes més o menys prefixades que havien seguit fins aleshores les reclamacions col-lectives de l'espai públic barceloní. Les accions peripatètiques massives tendeixen cada cop més a ignorar els grans senderis assignats, des de principis dels anys 80, per les litúrgies ciutadanes més o menys oficials, i s'entesten a generar diagrames estranys per a allò que havien estat les pràctiques protagonitzades per les multituds en moviment. La clau d'aquesta alteració del que havia estat la lògica topogràfica fins aleshores dominant, que treballava sistemàticament un repertori restringit d'indrets i trajectes -Passeig de Gràcia, Plaça de Catalunya, Ronda de Sant Pere-Via Laietana, Plaça de Sant Jaume, o Plaça de la Universitat, Pelai, Fontanella, Via Laietana, $\mathrm{Pla}$ de Palau, etc. - ha estat la irrupció en escena de corrents de crítica cultural que proposen la democràcia participativa com a alternativa al sistema de representació política basat en partits parlamentaris. Les protestes urbanes encapçalades per aquests moviments han alternat les singladures canòniques amb d'altres que usen la xarxa de carrers procurant desplaçaments inèdits $\mathrm{i}$ apropiacions desconegudes fins aleshores. Estem parlant de moviments que traslladen la seva desauto- 
rització de les grans institucions polítiques a través d'un qüestionament de la institucionalització política de què és objecte el mateix espai públic que tan vehementment reclamen.

Aquestes formalitzacions alternatives de la trama urbana no feien sinó advertir de quines eren les preferències culturals de moviments juvenils com els okupes (Martínez López; Gomà): la desrutinització de l'espai i del temps urbà; la generació d'esdeveniments que trenquen amb la quotidianitat; la provisió d'àmbits alliberats en què desplegar energies creatives alternatives; l'èmfasi en les qualitats més nómades de l'experiència vital urbana; tot plegat en la línia d'una vindicació global de l'herència situacionista, el referent principal del qual serà sempre la revolta del maig del 68 a París. El moviment okupa representa certament una fracció minoritària en els corrents de protesta, però ha tingut un paper estratègic per generar esdeveniments mediătics, de manera que les okupacions $i$ els desallotjaments han estat constants en l'etapa considerada, al mateix temps que les cases okupades han esdevingut autèntics centres d'activisme social alternatiu. A més, el moviment okupa ha acabat esdevenint una mena de referent no sols moral - per la seva imatge pública d'insubornabilitat - sinó també formal i formalitzador a l'hora d'usdefruitar la geografia urbana per fer-ne marc i vehicle per a l'expressió de sentiments i anhels col-lectius.

Seguint la tipologia proposada per Favre (34), les manifestacions okupes o afins -que la premsa i les fonts oficials "degudament autoritzades" solen qualificar de "radicals" o "antisistema"- es correspondrien a la variant de les iniciadores, caracteritzades per una relació amb l'àmbit politic institucional encara per establir (o que no s'establirà mai), sense representació política reconeguda i dotada d'una capacitat de convocatòria rares vegades massiva. Es tracta del reflex d'una organització embrionària i sovint desjerarquitzada, que es caracteritza per un vincle més aviat fort entre els manifestants, un acomodament conflictiu amb l'anomenat ordre públic, una relació feble amb els mitjans de comunicació (sovint àdhuc hostil), una imatge pública problemàtica o negativa i fortament focalitzada vers el futur. A partir d'aquests trets aquest tipus de manifestació pot diferenciar-se tant d'aquelles altres que Favre classifica com a manifestacions de crisi, orientades vers el present i molt sovint convocades des de les institucions com les que tipifica com a rutinàries, que remeten a un passat que s'encarreguen d'evocar. A més de la singularitat dels seus continguts, aquests moviments (en el sentit literal, de mobilitats), han procurat desacatar sistemàticament els senderis rituals ja institucionalitzats, usats de manera també sistemàtica per les marxes ciutadanes recolzades per partits o sindicats majoritaris o per aquelles altres convocades per les pròpies instàncies de poder en situacions d'emergència.

En efecte, al llarg de la primera meitat dels 9o, les marxes civils 
havien seguit les grans rutes rituals apuntades més amunt. Seguint aquests traçats preestablerts, el que feien els desplaçaments massius d'índole sociopolítica era exercir una certa lògica topogràfica, que consistia en la penetració en el nucli antic de la ciutat - Ciutat Vellades de l'exterior. Es partia d'un punt significatiu de l'Eixample i es practicava una mena d'incursió en el que havia estat l'interior de les muralles medievals, sovint per interpel-lar edificis institucionalment significatius ubicats al seu interior. Aquest moviment era alhora, per les condicions topogràfiques de la ciutat, una baixada, és a dir un descens en el sentit muntanya-mar. Aquestes actuacions implicaven al mateix temps desplaçaments que eren sempre en sentit sud-nord, o Llobregat-Besòs, si es vol, que és (segur que no per casualitar) el mateix sentit que segueix la numeració de tots els carrers de la ciutat, tret de la Diagonal. El nucli antic de la ciutat — per exemple la Ramblaperdia el paper protagonista que havia tingut fins al final de la Guerra Civil com a via fonamental de les demostracions polítiques i era vindicat quasi en exclusiva per apropiacions peripatètiques per part de moviments radicals de protesta, com ara okupes, feministes, gais, prozapatistes, etc.

Tot això canviarà a partir de la segona meitat de la dècada dels 90, $i$ amb una influència creixent dels moviments socials de signe anticapitalista, entre d'altres l'okupa. Per exemple, a la setmana del 20 al 27 de maig de 1999, diversos col-lectius van organitzar unes jornades titulades Trenquem el silenci, que consistien en una reivindicació activa del carrer com a lloc per a la creativitat expressiva, l'intercanvi comunicacional i l'anhel de les màximes cotes de llibertat. Les jornades van consistir en una articulació d'elements festius i de protesta. En arribar a la plaça de Catalunya, el mateix dia 20 , els marxants van aixecar diverses tendes de campanya, en una presa vindicativa del centre urbà que ja havia estat plantejada amb l'okupació de la plaça del is de juliol de l'any anterior. El dissabte va tenir lloc una rua vindicativa per la Rambla: un seguici de gent disfressada $i$ animada per grups de percussió va protagonitzar diverses performances contra la llibreria de la Generalitat i el Palau de la Virreina, seu del municipal Institut de Cultura de Barcelona. Els manifestants no van deixar de fer pintades contra els poders polítics i econòmics i empastifaren els aparadors de diverses hamburgueseries, la seu de La Vanguardia i de grans empreses com ara Telefónica. Altres actes simbòlics que interpel laven el sentit i el valor de l'espai públic van ser una colada massiva al metro de Liceu i una "requisa" de compreses en un supermercat del carrer del Carme, que van ser distribuides entre les dones que passaven pel carrer en aquell moment. El final de festa va tenir lloc al Passeig de Maria Cristina, a l'entrada de Montjuïc, l'indret on cada any té lloc la Fira de l'Automòbil, on es va posar en escena una performance d'un casament entre 


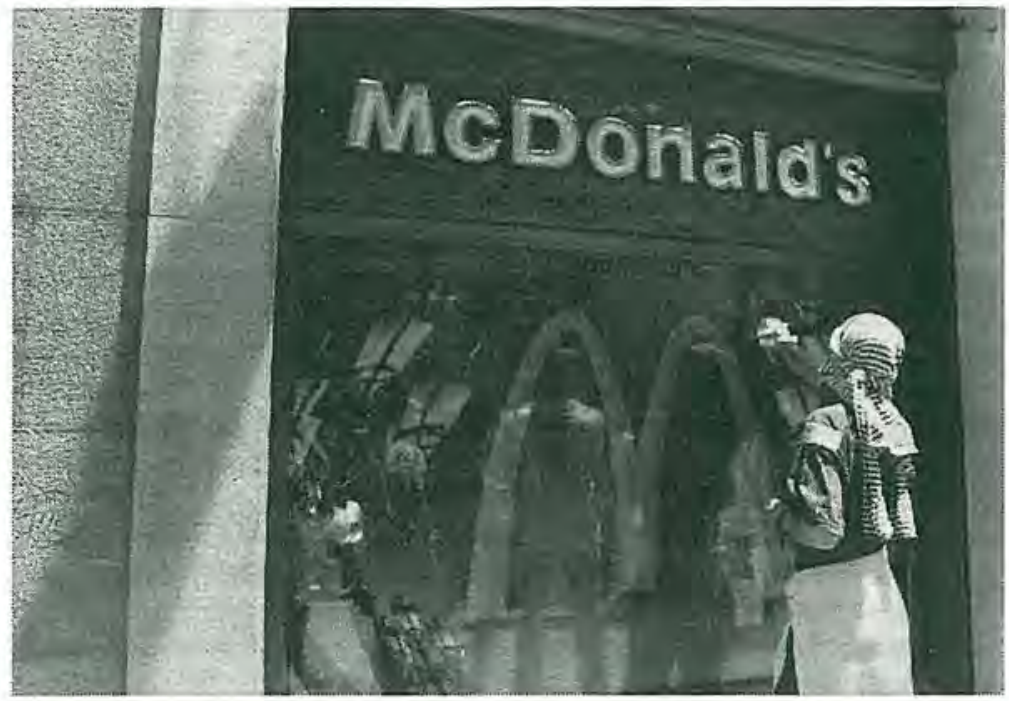

Foto $I$

Acció contra una hamburgueseria a les jornades de protesta del març de 1999

un personatge que encarnava el capitalisme i un cotxe vell - Merceditas"- que finalment era destrossat pels assistents.

En aquesta mateixa línia de desobeir no sols els traçats oficials de les manifestacions, sinó també l'orientació geogràfica que havien de tenir, el dissabte is d'abril del mateix any 2000 , milers de simpatitzants del moviment okupa que protesten contra l'especulació urbanística s'apleguen davant de l'edifici de la Universitat, però no baixen cap als centres de poder ubicats al cor de Ciutat Vella, sinó que pugen pel carrer d'Aribau. Durant quatre hores, els manifestants circulen per un itinerari del tot atípic i que no semblava excessivament prefigurat: carrers d'Aragó i Balmes, Ronda Universitat, carrers de Pelai i Fontanella, Via Laietana, Passeig de Colom, Portal de la Pau, etc. Al llarg del recorregut s'aturen davant certs punts significatius (delegacions d'Hisenda, comissaries, edificis reclamants), despleguen diferents formes de performance (crema i col-locació de banderes, pintades, escenificacions, penjada de pancartes, escridassades, actuacions festives) i acaben "alliberant" simbòlicament companys seus que havien ocupat el monument a Colom.

Aquesta pauta, consistent justament a desobeir les pautes topogràfiques de les apropiacions de caire fusional - car generen fusions efímeres- de l'espai públic a Barcelona, passa de ser exclusiva de corrents 
de dissidència social més o menys minoritaris a convertir-se en una tendència generalitzada que afecta mobilitzacions ciutadanes de més ampli espectre cada cop. Així, el 23 de març de 2000 , els dotze mil estudiants que protesten contra noves mesures en la política educativa surten -com sol ser habitual en les manifestacions estudiantilsde la plaça de la Universitat, però no segueixen per Pelai, Fontanella i la Via Laietana per desembocar al davant de la Generalitat, com feien sempre les marxes estudiantils. En comptes de seguir el camí ritual establert pel costum en les seves marxes públiques, sempre en sentit Llobregat-Besòs, els estudiants enfilen en direcció contrària cap a la plaça d'Espanya, per acabar assaltant tumultuosament el Saló de l'Ensenyament que organitzava el Departament d'Ensenyament i que s'estava celebrant en aquell moment al recinte firal de Montjuïc.

Hem vist que la reconsideració generalitzada del valor simbòlic de la xarxa viària que apareix recurrentment a partir de 1996 i que es repeteix amb motiu de les grans mobilitzacions antimilitaristes $i$ anticapitalistes de principi de la dècada del 2000 , culmina en les multitudinàries denúncies populars de la invasió de l'Iraq, a la primavera del 2003 i del 2004 , també amb una forta dosi d'espontaneitat i d'apropiacions insòlites de l'espai urbà. Han estat els moviments socials de signe anticapitalista els que han operat una descentralització en aquests tipus d'actuacions efímeres sobre la forma urbana, portant les seves manifestacions a barris com Gràcia, Sants, Hostafrancs o el Coll. En no pocs casos s'insinua una mena de "ninguneig" de les instàncies de poder, com si se les considerés indignes fins i tot de ser imprecades. Si de cas, els edificis on s'instal.len les institucions polítiques sols resulten aptes per fer-los víctimes d'escarni, com quan, després de burlar totes les vigilàncies, es va fer onejar a plena llum del dia una gran bandera negra amb el símbol okupa al pal central de l'Ajuntament, al setembre de 1997, en substitució de la bandera espanyola.

\section{OCUPADORS I OCUPANTS}

En el marc d'aquest reviscolament de la tradició protestària de Barcelona -mai del tot adormida en el període anterior al desallotjament del cine Princesa, amb puntes d'activitat tan importants com les protestes anti-OTAN al llarg dels 80 i contra la guerra del Golf a principis dels $90-$, algunes de les expressions més importants de vindicació proclamativa del carrer van usar una lògica ja abundantment desplegada en contextos festius. Es tracta d'apropiacions col-lectives de l'espai públic que consisteixen a indicar la presència simbòlica de determinades entitats, que són al-legories explícites de potències antisocials. Aquestes instàncies imaginades com a amenaçadores - bèsties reals o fantàsti- 
ques, encarnacions del desordre com ara diables, etc.- són representades dramatúrgicament penetrant en el si de la trama urbana, provinents de sota o de fora dels límits físics de la comunitat. Un cop injectades en la xarxa de línies i cruillles que conformen l'entramat viari, el seu avenç es veu primer entorpit i després definitivament frustrat pels veïns que han sortit al carrer per jugular el progrés de la potència negativa circulant pels canals que porten al centre del poble, el barri o la ciutat. Els nostres correfocs o els correbous són exemples de la posada en escena del drama del sotmetiment i posterior eliminació o expulsió de forces negatives externes que han aconseguit fer-se presents en el si d'una determinada morfologia territorial.

La primera aplicació d'aquesta translació d'un principi de manipulació festiva de la forma urbana a l'àmbit de les protestes civils, dins el període considerat, foren les protestes contra la celebració a la plaça dels Països Catalans de mítings de l'extrema dreta amb motiu del Dia de la Hispanidad. Aquestes concentracions feixistes havien tingut lloc ininterrompudament des de principis dels 80 , amb episodis freqüents d'agressions contra vianants indefensos, no sols al punt de reunió (la més emblemàtica de les primeres places dures de Barcelona, dissenyada per Piñón i Viaplana), sinó en el decurs de violentes marxes al centre de la ciutat, algunes tan brutals com la de 199I, quan desenes de persones van ser apallissades tan sols pel seu aspecte de "rojos", en un al-lucinant recorregut de dues hores pel carrer Tarragona, la Gran Via, la plaça de Catalunya, el carrer Ferran i Drassanes, sense que la Policía Nacional, present en tot moment, fes res per impedir-ho. A partir de 1998, la percepció que la presència de la ultradreta era una irrupció d'estranys $\mathrm{i}$ indesitjables que havia posseït la ciutat contra la seva voluntat es va traduir en expressions públiques que tractaven d'exorcitzar l'entitat aliena que havia aconseguit introduir-se malèvolament en el cos urbà.

S'explicità aleshores, en forma de drama urbà, l'enorme distància que separava l'ocupador de l'espai públic, que el fa seu legítimament mentre l'usa, i l'ocupant, potència aliena i contrària que es fa present per la força i de manera il-legítima, tot i que no per força il-legal El mateix 12 d'octubre de 1998, una nodrida manifestació de joves antifeixistes marxaren sobre el lloc on es produïa la reunió ultradretana des de la plaça de Sants, intentant accedir a la plaça dels Països Catalans per Badal i Brasil. A l'avinguda de Madrid toparen amb la policia que protegia l'acte feixista i que obligava els manifestants a dispersar-se. Una batalla campal es va desenvolupar després pels carrers Galileu, Sagunt, Vallespir i d'altres propers al carrer Numància. Més greus van ser encara els fets del Dia Nacional de España de 1999. Encapçalava la contramanifestació d'aquell any una pancarta on es podia llegir "No passaran", el vell lema antifeixista que al 1936 expli- 

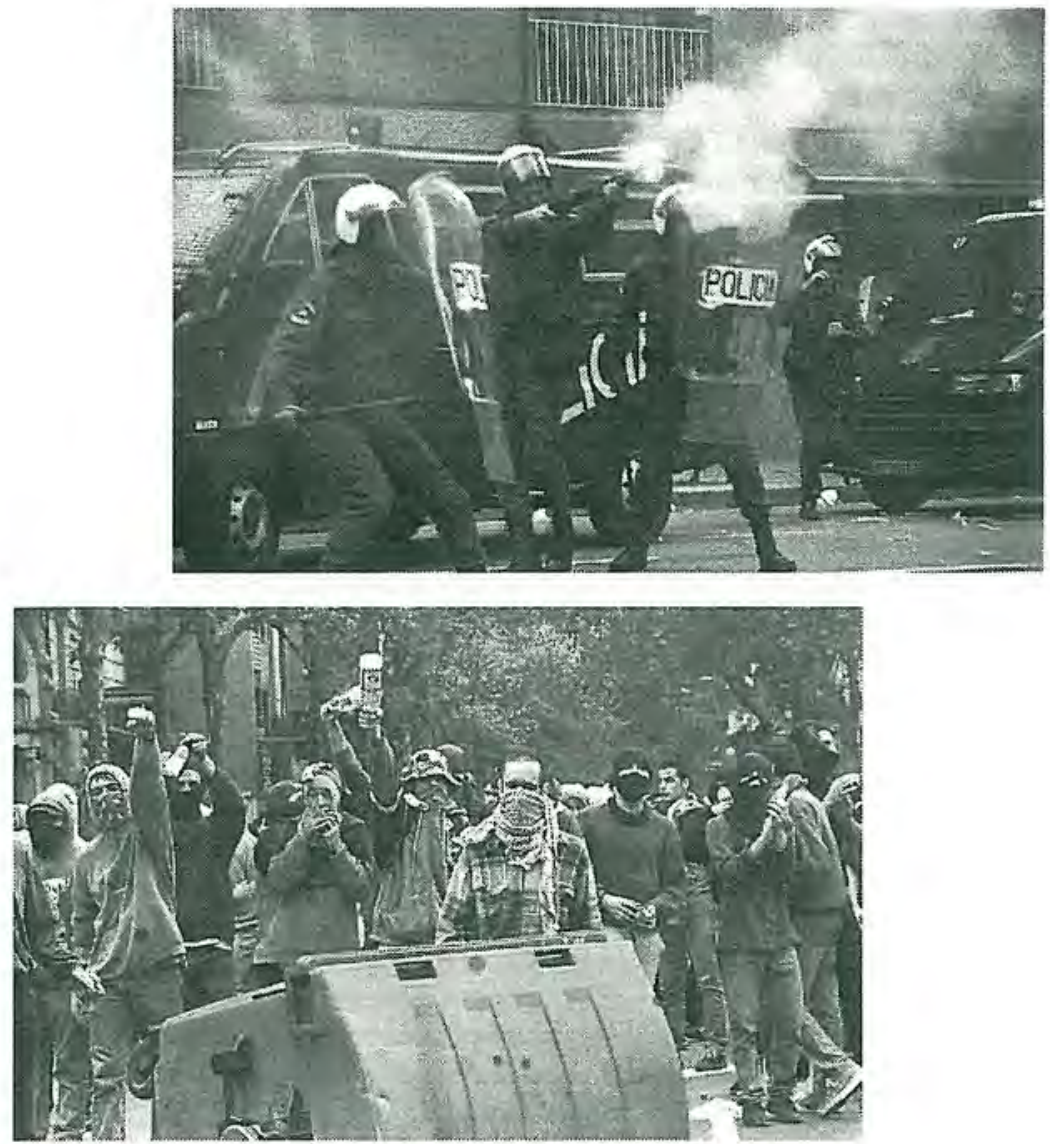

Fotos $2 i_{3}$

Manifestants $i$ policies en els enfrontaments del Día de la Hispanidad de 1999

cità la voluntat d'impedir l'accés a la ciutat a unes forces antipopulars i antiurbanes. Abans d'arribar a la seva destinació, la policia va interceptar violentament el seguici. Els aldarulls s'estengueren al llarg de la carretera de Sants i l'avinguda de Madrid i més d'una vintena d'aparadors d'entitats bancàries foren destruits i es van produir vint-i-sis detencions, en condicions que van motivar una perllongada polèmica pública sobre l'actuació policíaca. El 2000 una acampada popular al lloc de la concentració feixista, al davant de l'estació de Sants, va obligar les autoritats a traslladar la celebració ultradretana a Montjuïc, on 
des d'aleshores se celebra, encara que els aldarulls pels voltants s'hagin continuat produint any rere any.

Idèntica lògica es va reproduir l'any següent, com a resposta a la decisió del govern del Partit Popular de celebrar a Barcelona una parada militar el 27 de maig de l'any 2000 . La idea inicial de celebrar la desfilada del Dia de las Fuerzas Armadas a la Diagonal, tal i com s'havia esdevingut al maig de i981, poques setmanes després de l'intent de cop d'Estat de Tejero, va ser considerada inacceptable per una àmplia majoria de la població i àdhuc a les pròpies institucions polítiques governants a la ciutat, car s'anava a evocar, de manera inevitable, la imatge que al llarg de dècades s'havia ofert amb motiu de l'entrada de les tropes de Franco a Barcelona al gener de 1939, estampa renovada en les corresponents desfilades anuals de l'exèrcit sota la dictadura. El suggeriment de traslladar l'acte als voltants de la plaça de Pius XII, també a la Diagonal, però en direcció sud -és a dir, fent un moviment de sortida- va ser descartada quan les autoritats acadèmiques es van negar a tancar les facultats de la zona universitària, precisament pel que tenia de record del que havia estat una actuació tan recurrent del règim franquista com ara la de clausurar les universitats. Després de considerar altres alternatives, la decisió final va ser ubicar l'esdeveniment en una zona de ningú, a la muntanya de Montjuïc.

Però això no va aconseguir apaivagar la indignació d'una part important de la ciutadania de Barcelona. De fet, es reproduïa simbòlicament una reacció de rebuig enfront de la presència intrusa dels militars que era la mateixa que ja s'havia viscut abans ben tràgicament als carrers de la ciutat, al juliol de 1909 o al de 1936 , quan la majoria de la població, expressant una hostilitat antifeixista sense límits, va impedir per la força la circulació de les tropes pels carrers de la ciutat. El dissabte 20 de maig de 2000 , unes cent mil persones van desfilar des de la cruilla del Passeig de Gràcia amb la Ronda Sant Pere fins al Moll de la Fusta, seguint l'itinerari habitual que havien utilitzat les grans marxes contra l'OTAN a la dècada dels 80 . Des d'aquell mateix dia, un grup important d'antimilitaristes acamparen sobre la gespa del centre de la plaça d'Espanya, com si vigilés un espai urbà que anava a ser deshonrat indignament per uns intrusos inacceptables. Quan faltaven poques hores perquè es perpetrés el que molts entenien com a deshonra de l'espai públic, la policia va desallotjar violentament els acampats.

El 27 de maig, al matí, el carrer Lleida i l'avinguda de Rius i Taulet eren testimonis d'un acte militarista que havia estat denunciat com el déjà vu d'un passat ignominiós, presidit per les autoritats de l'Estat, fins i tot aquelles que havien propiciat l'intent de fer escapolir l'esdeveniment lluny del cor de la ciutat, en el sentit literal de centre urbà i en el doble sentit metafòric de múscul que impulsa i recull els fluxos urbans $\mathrm{i}$ - a la manera com advertia el títol d'una reeixida sèrie televi- 
siva de principis de la dècada del 2000- de lloc que acull els sentiments bàsics dels habitants de la urbs. Al mateix temps, des de la plaça del Centre, centenars de joves iniciaven una marxa per l'avinguda de $\mathrm{Ma}$ drid sobre la plaça d'Espanya, porta de Montjuic. A l'alçada de Joan Güell toparen amb un destacament policiac que els barrà el pas violentament. En petits grups els manifestants accediren als voltants del carrer Tarragona i foren de nou interceptats per les forces policíaques, dispersant-se pels carrerons del barri gitano d'Hostafrancs i pel parc de l'Escorxador, on es reproduïren els enfrontaments amb la policia $i$ amb grups filonazis que acudiren a ajudar-los. En aquells mateixos moments, tenia lloc un massiu acte de desgreuge a un altre parc públic, el de la Ciutadella. Desenes de milers de persones - moltes més que les que havia aconseguit aplegar l'exaltació militar que es desenvolupava a poca distància- desautoritzaven el que s'interpretava com una utilització indigna dels carrers de Barcelona. L'endemà, joves independentistes netejaven amb lleixiu la calçada de l'avinguda Rius i Taulet fins al Poble Espanyol, és a dir, la via per la qual el dia anterior havien circulat les tropes, deixant ben clara la idea que aquell espai havia estat literalment embrutat per una presència definible com a contaminant. S'evocava d'aquesta forma la dramatúrgia que havia servit als habitants de Barcelona, al segle XIX, per expressar el seu refús per l'exèrcit $i$ la monarquia, escombrant els carrers que havien trepitjat els visitants indesitjables el dia anterior.

La mateixa lògica formal i formalitzadora - una energia o entitat detestable intenta fer-se present al si de la comunitat $i$ és detinguda a les seves portes o en el seu avanç per la trama de carrers- es va reproduir l'any següent amb motiu de la pretesa celebració d'una cimera del Banc Mundial. També retrobem aquí, ja plenament cristal-lirzada i assumida per mobilitzacions socials majoritàries, maneres inèdites d'apropiació de l'espai públic que havien estat anticipades pels moviments socials d'inspiració neosituacionista, com ara l'okupa. En concret, el divendres is de juny de 2001 , es duu a terme una manifestació pels carrers de Barcelona que s'inspira en les posades en escena de Reclaim the streets, corrent inaugurada amb motiu de la cimera del G-7 a Colònia i que havia tingut expressions a diferents ciutats del món. Es tracta de desfilades mig reivindicatives, mig carnavalesques, en les quals la confusió deliberada entre festa i revolta apareix explícita i que funcionen com a incursions sedicioses que irrompen/interrompen en barris financers $i$ bancaris o a l'entorn de les grans multinacionals. A Barcelona, la manifestació va iniciar-se a la plaça de la Universitat i estava presidida per un camió dotat d'un potent amplificador, a través del qual sonava música tecno, seguint el model de les love parades. Al llarg de la rua vindicariva, es produïen accions simbòliques, com el repartiment de llibres "requisats" a la Casa del Llibre o l'atac simbòlic contra la botiga de Man- 
go del Passeig de Gràcia. Una bicicletada pel Passeig de Gràcia va ser atacada per la Policia Nacional, que en un moment determinat va esgrimir les seves armes de foc a causa de la "perillositat" dels ciclistes.

Les protestes contra la presència del Banc Mundial reproduien una mecànica simbòlica idèntica a la que s'havia vist en la desfilada militar de l'any anterior: assignació de la qualitat d'indesitjable a una presència exterior que pretenia imposar-se al cor de la ciutat. Curiosament, la presència física contra la qual es protestava ni tan sols es va arribar a produir, car la por al que pogués passar al carrer va fer que els convocants s'ho repensessin i canviessin d'opinió. La cimera es va fer finalment on line. Els actes contra la presència dels representants del Banc Mundial ja estaven decidits i es va pensar que els motius de la protesta continuaven vigents, hi fossin o no presents físicament els interpel-lats. Així, doncs, es va mantenir la convocatòria d'una gran manifestació, el 24 de juny de 2001 , després d'una revetlla popular a la platja de la Mar Bella, l'escenari de la qual havia de ser el Passeig de Gràcia. La pretensió dels moviments anticapitalistes d'usar un carrer cèntric, des de l'u de setembre de 1977 escenari predilecte dels actes de masses patrocinats institucionalment, es desvetllava, segons els arguments de la delegació del govern central a Barcelona, com a inacceptable, de manera que el govern va imposar el trasllat de la manifestació contra el Banc Mundial al Passeig de Sant Joan. Tot i això, una decisió judicial va mantenir la marxa en l'itinerari previst inicialment. La contribució dels mitjans de comunicació - des de feia temps compromesos amb una campanya de criminalització contra els moviments antiglobalització- va ser proverbial. Resultava significatiu com treballaven els mitjans de comunicació a partir d'apreciacions espacials relatives als sentiments que poden atribuir-se a un carrer. Així $\mathrm{El} \mathrm{Pe-}$ riódico de Catalunya titulava un informe el mateix 24 de juny: "El Passeig de Gràcia tem actes radicals durant la marxa". La profecia va acabar autocomplint-se $i$ es van produir greus incidents al Passeig de Gràcia, que van ocasionar -i segons diversos testimonis van ser ocasionats per- una violentíssima actuació policíaca, amb desenes de manifestants d'actitud pacífica ferits.

Aquesta mateixa manera d'expressar, a través d'una manipulació simbòlica de la trama urbana, el rebuig a una presència estranya $i$ indesitjable es va produir amb motiu de la cimera de caps d'Estat de la Unió Europea el I4, I5 i i 6 de març de 2002. De nou, les autoritats van poder percebre fins a quin punt la ciutat podia mostrar-se esquerpa i inhospitalària davant una entitat que $s$ 'havia fet present $i$ era assenyalada com a indesitjable. Durant tres dies, els mandataris internacionals van haver de reunir-se amagats en un recinte fortificat, a les portes de la ciutat, a l'extraradi, com si assumissin la seva condició de matèria estranya, que l'urbs es negava a rebre, sense gosar ni tan sols acostar- 
se al seu centre. Els convidats - de qui? No pas de la ciutat, és clarno van sortir d'un ample perímetre a la zona de Pedralbes, tancat amb una muralla de ciment $i$ dobles reixes que literalment els engabiava. Per descomptat que no van experimentar res que pogués assemblar-se a una benvinguda, ja que l'acte va tenir lloc sense garlandes als carrers, sense banderoles, sense arcs triomfals, sense públic a les voreres. Ja d'entrada els líders europeus van haver d'experimentar una forma d'allò que es coneix com l'efecte túnel que els duia des de l'aeroport fins a l'hotel Juan Carlos I, sense el menor contacte amb una ciutadania que era percebuda - en certa mesura amb raó- com una amenaça per la seva seguretat. De fet, la recepció oficial que havia de celebrarse un dels dies de la reunió al Palau de la Generalitat va haver de traslladar-se al MNAC (Museu Nacional d'Art de Catalunya), al Palau de Montjuïc, també lluny d'un nucli urbà feréstec i d'una ciutadania isarda. Barcelona, un cop més - com tantes vegades abans al llarg de la història - assetjada, es va trobar ocupada per vuit mil policies destinats a vigilar uns habitants que calia mantenir a tota costa lluny, a ratlla. Ells, els poderosos de la terra, es van trobar, en canvi, deslegitimats i inhabilitats per fer ni tan sols un petit tomb pel down town barceloní.

Al llarg dels dies que va durar la cimera, manifestacions de tota mena van recórrer la ciutat en totes direccions i a tota hora. El dia 9 tenia lloc una edició del Reclaim the streets, el susdit moviment internacional d'apropiació dels carrers. El diumenge ro, una altra demostració massiva contra el posteriorment derogat Plan Hidrológico Nacional utilitzava la Ronda de la Universitat per anar de la Plaça de la Universitat a la Plaça de Catalunya, un recorregut gairebé inèdit fins aleshores. Uns dies després, desenes de milers de persones convocades pels sindicats baixaven per la Via Laietana des de plaça Urquinaona, seguint en aquest cas l'itinerari ritual que marquen les marxes sindicalistes a Barcelona. Durant les tres jornades de la cimera s'intensificaren les apropiacions expressives del carrer, en un moviment que impregnava gairebé la totalitat de la trama urbana barcelonina. Una bicicletada es movia al llarg de la Gran Via, al mateix temps que altres manifestants baixaven a peu des de la Sagrada Família, aturant-se davant les seus de diferents multinacionals. Poc després, es va produir una manifestació davant del Liceu, a la Rambla, i una concentració a la Plaça dels Àngels, davant del MACBA. El darrer dia de la cimera, el í de març, a l'entorn de quatre-centes mil manifestants desfilaven Via Laietana avall i pel Passeig de Colom fins al Portal de la Pau en contra de la mundialització, en una explosió d'heterogeneïtat que contrastava amb les masses fosques dels piquets de policia que no deixaren de vigilar els manifestants al llarg de tot el recorregut. Barcelona havia tornat a demostrar de què estava feta: la seva tants cops provada capacitat d'exprimir al màxim les capacitats creatives i expressives 
dels seus carrers. Abans de finalitzar la marxa van començar un seguit de violents aldarulls que afectaren la part baixa de la Rambla $i$ del Paral-lel, amb diversos ferits i detinguts, actes que van ser denunciats com una actuació desproporcionada de la policia. L'ombra dels esdeveniments recents a Göteborg i a Gènova, en què les forces policíaques van fer ús de les seves armes de foc, planava sobre l'ambient.

\section{PERFORMANCES DE FACANA I ALTRES IMPREGNACIONS URBANES}

El fenomen va repetir-se l'any 2003 amb les grans protestes contra la intervenció nord-americana a l'Iraq. Com va succeir l'any següent contra la manipulació informativa del govern del Partit Popular després de l'atemptat de l'I de març, la tècnica utilitzada en les apropiacions de l'espai urbà va ser la de la incursió, és a dir una marxa que desemboca - literalment, si considerem el funcionament hidrostàtic dels usos fusionals que rep l'espai urbà- en una mena d'assalt o presa metafòrica de la concreció espacial de les instàncies de poder, aquelles que hom considera responsables d'una determinada situació social o política que es considera injusta o agreujant. Un cop liquats en forma de concentració en un punt de partida, els vianants que s'identifiquen com a expressió d'un sector social afectat per un contenciós o altre, inicien el seu desplaçament $i$ es van obrint pas per determinats canals de la retícula urbana, considerats com a simbòlicament pertinents, aturant-se en certs punts eloqüents del trajecte, per fer-se finalment presents davant de les portes dels poders ofensius o del lloc on s'estan produint esdeveniments en què el conglomerat humà cristal-litzat per a l'ocasió s'involucra a favor o en contra. L'indret és ocupat i les instàncies que l'ocupaven es repleguen a l'interior de l'edifici que les hostatja; a fora, els reunits gaudeixen de la sensació que han viscut una victòria efímera. Es tracta del que Dorothy Noyes anomena performances de façana, en què un grup humà es fa present al davant d'un edifici i realitza una actuació de les que la tradició festiva popular ja tenia sota modalitats com ara les enramades o les caramelles.

Tant a la primavera del $2003 \mathrm{com}$ a la del 2004 multituds reunides van dur a terme mobilitats consistents a presentar-se davant llocs simbòlicament significatius, als quals s'atribuila una condició d'alguna forma malèfica o extraordinàriament indesitjable. En no poques oportunitats, les expressions de desafecte envers les instàncies interpel-lades podien resoldre's amb agressions contra els edificis en què tenien la seva seu, en forma d'apedregaments, pintades, llançament d'ous, tomàquets, bosses d'escombraries, ampolles o pintura, etc. La lògica d'aquesta mena d'actes és sempre la mateixa: una potència gairebé maligna viu allà dins, darrere dels murs de l'edifici, cau que hostatja una entitat asso- 
ciada a energies del tot negatives. Aquests indrets són els temples del poder polític o econòmic i, per aquesta causa, llocs sagrats-maleïts. Els agressors els apedreguen o els empastifen: no apedreguen o empastifen un immoble, sinó allò que hi habita.

Són gairebé innombrables les ocasions en què ha estat interpel-lada la Delegació del Govern a Barcelona, a la plaça Palau, sovint de manera violenta. També ha estat de vegades violentament impugnat el Palau de la Generalitat, sobretot en les manifestacions estudiantils que han acabat davant de les seves portes, amb la consegüent càrrega policíaca, algunes tan violentes com les que van patir els estudiants de batxillerat i formació professional a les manifestacions del 9 de novembre de 2000 . Igualment ha estat objecte de simulacres d'assalt la seu del Parlament de Catalunya, al Parc de la Ciutadella, com quan es van produir les manifestacions estudiantils contra la repressió policíaca, el Io de març de 1999, o contra la Ley de Ordenación Universitaria, el 21 de novembre de 2002.

Alguns edificis veuen explicitades recurrentment les seves connotacions malignes. Són poques les manifestacions que, en passar pel davant, seguint la baixada ritual per la Via Laietana fins a la plaça de Sant Jaume o fins a la Delegació del Govern, no dediquen a la Prefectura Superior de Policia la seva atenció ofensiva. Ja s'ha fet esment del virulent

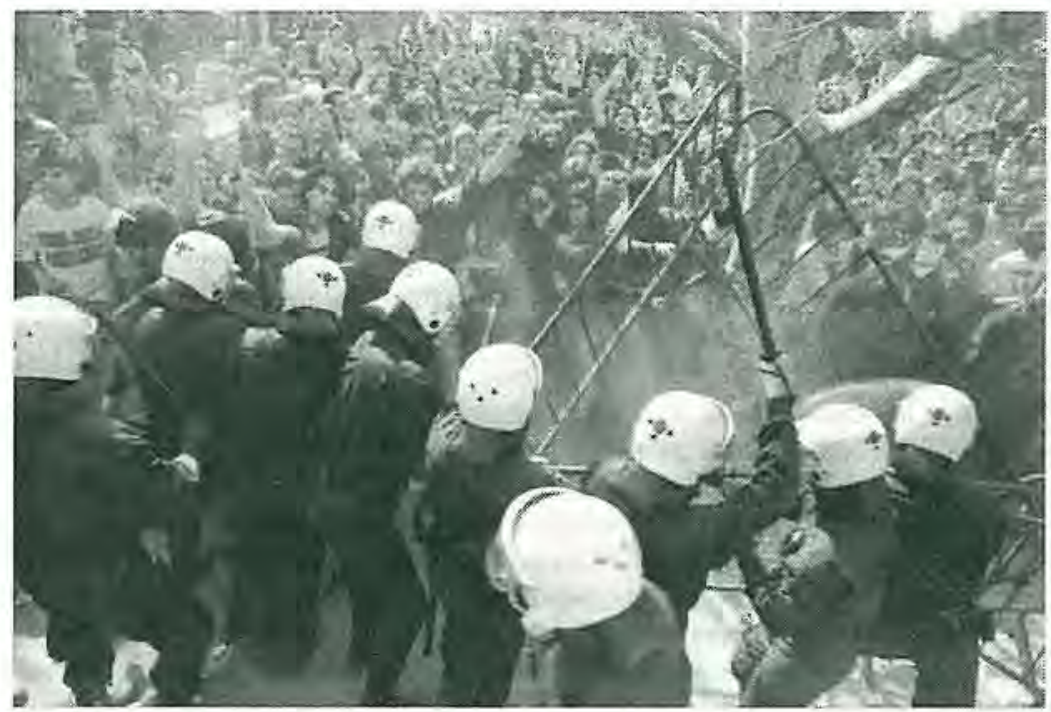

Foto 4

Manifestació davant el Parlament de Catalunya el to de març de 1999 
atac contra aquell indret d'infausta memòria - escenari de la pràctica sistemàtica de la tortura contra detinguts polítics durant el franquisme- en el decurs de la manifestació de protesta contra el desallotjament del cinema Princesa, quan milers de joves van obligar el cos de guàrdia a refugiar-se a l'interior i suportar una bona estona d'assetjament. Val a dir que les grans protestes de febrer i març de 2003 contra la guerra d'Iraq van usar intensament aquesta modalitat d'acció pública consistent a atacar o injuriar el frontis d'un edifici, com una forma desplaçada d'agressió contra allò que conté. Entre els edificis implicats es troben els McDonald's de la Rambla, l'ambaixada americana i la seu del Partit Popular. Contra aquest darrer indret les escenificacions van incorporar dramatitzacions "fortes", com les consistents a llençar-hi sang, fems i despulles animals.

Una altra fórmula d'apropiació expressiva de l'espai urbà han estat, en els darrers anys, les acampades. Als mesos de febrer i març de 2003 van fer-se campaments davant l'Ajuntament i la Generalitat, a la plaça de Sant Jaume; a la plaça de Francesc Macià, ben a prop de la seu del Partit Popular, al carrer Urgell, i a la plaça Palau, enfront de la Delegació del Govern. En aquests casos, els campaments funcionaven com una variant de performance de façana, en què s'insinuava un setge o una vetlla simbòlics al davant d'edificis institucionals o seus polítiques.

De vegades, les persones acampades poden combinar aquesta dimensió simbòlica com a forma de protesta amb una funció del tot instrumental, com és senzillament la de viure-hi, car no es té cap altra alternativa d'allotjament. Aquest va ser el cas dels campaments d'immigrants eslaus, magrebins o subsaharians que es van instal.lar a diferents punts de la ciutat al llarg del periode estudiat. El més important i problemàtic va ser el que va ocupar una part de la Plaça de Catalunya entre gener de 1999 i agost de 2001 . El dia 6 d'aquell mes, la Guàrdia Urbana va expulsar els acampats, que van traslladar-se a la plaça André Malraux, a prop de l’antiga estació del Nord. Allà, la tarda del I6 d'agost de 200I, una brutal intervenció de la policia encerclava i capturava en massa 166 dels immigrants sense papers que havien fet de la plaça la seva llar. En el mateix moment que els seus representants estaven negociant amb les institucions a la Delegació del Govern, desenes d'agents antiavalots de la Policia Nacional s'abalançaven sobre els acampats, indefensos. Molts dels que van escapar van ser caçats per la policia, que va passar-se diverses hores voltant pel barri, detenint qualsevol persona que presentés una pell massa fosca, entre les quals hi hagué alguns turistes. La guàrdia urbana va encarregar-se de donar suport logístic a l'operació i va tancar tots els accessos i túnels de l'estació de metro de Triomf, per assegurar-se que cap d'aquells "desgraciats" pogués escapar del parany en què es va convertir l'indret. Les esfereidores imatges de la policia arrossegant com bèsties a persones 
que no havien comès cap delicte i a les quals s'acusava de ser "il-legals", ens col-locaven davant d'uns nivells d'ignominia difícilment superables, incompatibles amb la condició de país civilitzat i democràtic de què tant blasonen els representants institucionals. A l'endemà, tant la Generalitat com l'alcalde de Barcelona, Joan Clos, feien declaracions públiques defensant l'actuació de la delegada del Govern central, la sinistra Julia García Valdecasas. Les tres administracions apareixen així conjuminades en la defensa d'una acció que aplicava de la manera més brutal la llei d'estrangeria que s'acabava d'aprovar al parlament espanyol.

La tendència apuntada cap a una intensificació en les apropiacions de l'espai públic barceloní a càrrec de cada cop més grans coalicions de vianants, que manipulaven el paisatge urbà de manera alternativa a la institucionalitzada, va assolir el seu màxim nivell amb motiu de les protestes contra la guerra de l'Iraq, al març i l'abril de 2003. A més de manifestacions que feien recorreguts clàssics, des del dia de l'esclat de la guerra - el Ig de març - i pràcticament a diari, els estudiants van dur a terme interrupcions-irrupcions constants, en punts distants els uns dels altres, amb actuacions imprevisibles que funcionaven com una mena de metàstasi de protesta que afectava el conjunt de la trama urbana. Després de la cadena humana entre l'ambaixada nord-americana i la seu del PP, el 29 de març, una multitud provinent de tots els barris de la ciutat $i$ de les poblacions de l'extraradi, amb la participació d'un bon nombre de veins de la zona, va inundar els barris alts de Barcelona - Tres Torres, Sarrià, Pedralbes- que mai abans havien aparegut "contaminats" per les agitacions ciutadanes al carrer. Grans manifestacions de centenars de milers de persones, convocades per la Plataforma contra la Guerra, feien passeigs col-lectius desconeguts fins aleshores, com el que circulà pel Paral-lel entre la Plaça d'Espanya i el Pla de Palau, el 22 de març, o entre la Plaça d'Espanya i la Plaça de Tetuan, omplint una bona part del traçat de la Gran Via de les Corts Catalanes, el I2 d'abril, o bé recuperant-ne d'altres, com passà amb la manifestació del is de febrer, la més nombrosa de les que s'han celebrat mai a Barcelona.

La protesta va enginyar en aquells moments altres maneres d'involucrar el conjunt de la ciutat, algunes ja assajades, com la instal-lació de senyeres, llençols o domassos, que servien -i serveixen-per protestar davant d'un fet o per celebrar una determinada identitat. En aquestes ocasions, la convocatòria pren el caire d'un autèntic plebiscit, en què són les finestres i els balcons de les cases els convidats a pronunciar-se, com va passar a Barcelona amb motiu dels primers Onzes de Setembre o arran de les Olimpíades del 1992. A partir de l'esclar de la guerra de l'Iraq, a la primavera del 2003, col-locar el símbol acordat a l'exterior de l'habitatge propi — pancarta, senyera, ban- 
dera pacifista - constituí el gest bàsic, que generava una mena de manifestació disseminada que comprometia tota l'extensió urbana.

L'equivalent sonor d'aquest mecanisme d'impregnació de la totalitat de la xarxa seria la cassolada, una tècnica de concerniment de la trama urbana en la seva totalitat que no s'havia aplicat mai a Catalunya i que va convertir-se en un dels elements més genuïns de les mobilitzacions contra la invasió de l'Iraq. Milers de persones van sortir al carrer o es van abocar a les balconades i finestres de llurs cases amb l'única finalitat de produir soroll, al mateix temps que molts cotxes feien sonar els clàxons $\mathrm{i}$ els vianants picaven amb els encenedors, claus o els objectes més inversemblants contra un semàfor, un pal de trànsit, el suport metàl-lic d'un tendal o d'una tanca publicităria, $\mathrm{o}$, simplement, picaven de mans. De vegades, l'acció va ser la conseqüència de convocatòries centralitzades, però moltes altres vegades l'ocupació sonora de l'escenari urbà va ser espontània. De sobte, d'algun lloc indeterminat, a les to del vespre, començava a arribar el soroll d'una cassola, immediatament, com un ressort automàtic, altres sons s'hi afegien a l'anterior $i$ contribuien a estendre, igual que una catifa, la protesta. La imatge produïda és la d'una ciutat que ha esdevingut una mena d'ésser viu colossal, un gegant que es desperta del seu somni per emetre un impressionant rugit, les dimensions dels quals es magnifiquen especialment a causa de la franja horària en què la protesta s'expressa: la nit, en un període - la primavera- en què per la temperatura nocturna les portes dels balcons $\mathrm{i}$ les finestres acostumen a romandre tancades. El pas del silenci de fons urbà a la remor, el murmuri, el brogit i l'esclat del bram sonor, adquireix llavors unes connotacions d'efervescència veinal inqüestionable: aquí s'hi exemplifica clarament com el soroll esdevé la manifestació més precisa d'un estat collectiu de comunitat emocional i ideal.

Això no vol dir que s'hagi descuidat l'ús de les grans línies per les quals transcorrien les marxes massives a Barcelona. De fet, en el període considerat s'han produït les dues marxes més multitudinàries que ha conegut la ciutat, que implicaren una autèntica inundació humana del centre urbà, amb xifres difícils d'establir, però que van ser presentades per sobre del milió i mig d'assistents. Es tracta de la primera gran manifestació contra la guerra d'Iraq, el 15 de febrer de 2003 i la de condol per l'atemptat a Madrid del in de març de 2004 , que va celebrar-se a l'endemà. En aquest darrer cas veiem fins a quin punt ni tan sols les ocupacions tumultuoses del centre de la ciutat convocades des dels propis governs són fiables ni s'emmotllen al guió que preveu per a elles la funció d'acudir en auxili d'institucions polítiques que se senten en perill. A la manifestació solidària amb Madrid del Iz de març va passar el mateix que amb la de protesta — també molt massiva - contra la mort d'Ernest Lluch a mans d'ETA, el 23 de novembre de 2000 . 
En totes dues ocasions, els reunits no van assumir el paper de figurants passius en un acte promocionat oficialment, sinó que van convertir la seva presència en un acte de protesta contra algunes de les autoritats que havien convocat l'acte i que presumptament n'eren els beneficiaris, tal com va passar en ambdós casos als alts dirigents del Partit Popular, que pretenien presidir la manifestació i que acabaren escridassats i fugint del mateix públic que en principi se suposava que hi havia acudit per recolzar-los.

La culminació - potser provisional-d'aquest procés de vindicació activa del dret a usar el carrer per a alguna cosa més que anar i tornar de treballar, es va produir la nit del 13 de març de 2004. Davant la manipulació escandalosa que el Partit Popular i els mitjans de comunicació al seu servei -és a dir, gairebé tots - van intentar fer de l'autoria de l'atemptat que acabava de costar la vida a dues-centes persones a Madrid, milers de persones van sortir al carrer per exigir la veritat. Moltes van respondre a convocatòries rebudes a través de missatges de telefonia mòbil o del correu electrònic, seguint un mètode de transmissió boca-orella que ja havia demostrat la seva eficàcia a Barcelona en grans mobilitzacions històriques, com la vaga de tramvies de 1951. D'altres van acudir per inèrcia a cites sobreenteses al davant de la seu del Partit Popular, a Canaletes o a la plaça Sant Jaume. La gent del carrer se sumava espontàniament a les marxes $\mathrm{i}$ concentracions improvisades, que arribaren a aplegar milers de persones. Una enorme cassolada que ningú havia convocat sonà a les ro de la nit. En aquesta ocasió es demostrava no sols el vell protagonisme de les multituds a la història sinó fins a quin punt és falsa la premissa segons la qual aquest tipus de mobilitzacions són inoperants. A l'endemà, la transformació en vots de la immensa pressió exercida per anònims vianants reunits, aconseguia derrotar, de manera humiliant, el govern de José María Aznar.

\section{BARCELONA: EL SÒLID I EL VISCÓS}

Aquest inventari i aquesta reflexió entorn dels usos no ordinaris del centre urbà de Barcelona a finals del segle XX $\mathrm{i}$ principis del XXI ha volgut ser una prova de com la trama viària d'una ciutat pot ser objecte d'apropiació per part d'uns usuaris - els simples vianants- que poden fer-ne alguna cosa més que un sistema de passadissos per anar $i$ tornar de compres o de la feina. Les coalicions de vianants que duen a terme operacions diagramàtiques per determinats carrers i places atorguen d'aquesta manera un valor afegit als escenaris de la seva vida quotidiana, que, de sobte, esdevenen els elements d'un llenguatge col-lectiu utilitzat per qüestionar els poders hegemònics a la societat. 
El carrer veu reconeguda d'aquesta forma la seva condició d'autèntica institució social al servei d'una democràcia participativa que aprofita la mínima oportunitat per exercir-se, a les bones o - si es veu obstaculitzada per emergir - a les dolentes. És el carrer, en efecte, on les mobilitzacions i els moviments socials ho són al peu de la lletra, és a dir, on les agitacions socials prenen $\cos$ - també en un sentit literal-i es converteixen en fluxos humans que ocupen un espai que es veu convertit d'aquesta manera en el que en principi ja era: públic, és a dir accessible a tots per a finalitats que no han de ser per força sempre submises i collaboradores.

Aquesta Barcelona de què hem parlat és aquella en què encara a hores d'ara sobreviu un vell esperit de rebel.lia i desconfiança envers els poderosos. D'aquesta ciutat res en saben - no volen i no poden saber- els responsables de la seva concepció i gestió en tant que "model". Són aquests els que han fet que Barcelona retorni als mateixos postulats monumentalistes i grandiloqüents de l'arquitectura de finals del XIX i de l'arrogància projectadora del racionalisme; a la teatralitat barroca que extreu dignitat de la seva autoexhibició permanent; a la ininterrompuda usurpació capitalista de la ciutat, expressada, com sempre, en clau d'especulació massiva, terciarització i posada al servei dels requeriments de la tècnica i del mercat; desdeny per solucionar -avui ni tan sols per alleugerir-l'endèmic problema de l'habitatge; la idea fixa de colonitzar d'una vegada per totes les zones de la ciutat que es resistien al deure de transparència; una arquitectura cada cop més espectacularitzada, ansiosa d'impactes visuals fàcils, que s'estima per damunt de tot allò que és banal; un dirigisme absolutista cap a les pràctiques reals dels ciutadans, que es voldrien veure fiscalitzades i monitoritzades, i l'espontaneïtat de les quals es contempla com un perill a exorcitzar; l'arquitecturització sistemàtica de la totalitat de l'espai públic i el projecte de convertir els seus usuaris en consumidors; la tematització de la ciutat, la proliferació dels simulacres i la festivalització del temps urbà; i finalment la condemna als sectors socials més desfavorits a viure l'exclusió del ple dret a la ciutat.

Enfront d'aquesta voluntat de convertir l'espai urbà en un escenari sota control, monitoritzat, adient als interessos d'aquells que creuen posseir-lo, les multituds que han ocupat els carrers en certs moment àlgids de la seva història -també recentment- han posat de manifest, un cop més de manera inequívoca, per a què pot servir i de qui és sempre, en darrera instància, el carrer. La vida urbana ve a assemblar-se a un magma autoorganitzat, a un plasma en condicions d'esdevenir qualsevol cosa en qualsevol moment. No s'atura; no es pot aturar; no en sap. Troba en l'oscil-lació permanent una font, paradoxal si es vol, d'estructuració. Enfront d'aquesta massa d'esdeyeniments que es neguen a cristal-litzar, l'urbanisme sovint sembla que pretengui orientar les percep- 
cions i les conductes tant dels grups com dels subjectes psicofísics. Per a molts urbanistes el destinatari de les seves intervencions ve a ser com una massa passiva que es plega submisament als seus designis. Ara bé, més enllà dels projectes dels urbanistes, hem vist com són els practicants de la ciutat, els transeünts, els qui creen un univers polièdric, fet de moviments regulars o espasmòdics, moleculars o massius.

A les acaballes del segle Xx $i$ als primers anys del XXI, les riuades humanes que van ser vistes fluent pels carrers de Barcelona, cada any per primavera, ens demostren en el pla de la gran història el que l'activitat ordinària, dispersa i difusa de les munions quotidianes, ja ens havia posat de manifest: que l'urbà no és res més que una tasca que la societat fa sobre ella mateixa, fent-se i desfent-se sense descans, però que mai no es dóna a ningú perquè hi vegi el resultac. Des del punt de vista del polític o del planificador, la ciutat és pensable, fins i tot somniable; al contrari, l'urbà en realitat és inintel.ligible: diu massa coses com perquè se n'entengui alguna o perquè el conjunt aparegui com un tot coherent. Estructuralment, formalment i funcionalment la ciutat pot ser prevista; l'urbà, en canvi, no. L'urbà és, per principi, una articulació indefinida i irregular, els moviments de la qual són impredictibles. És una trama interminable de diagrames, d'esquemes en filigrana, de mapes inconcebibles, generats sobre la marxa pels desplaçaments quotidians o excepcionals dels simples passants. Encara no s'ha fet prou per pensar seriosament qui són i què es pot esperar d'aquesta munió de cossos sense nom ni biografia que es belluga pels carrers.

La historia de la Barcelona del darrer segle i mig no ha estat sinó la d'un dilatat episodi d'aquesta lluita a mort entre la ciutat concebuda i la ciutat practicada, entre la polis i l'urbs, entre la socialització i la politització, entre l'estabilitzat i el magmàtic. Sabem que la ciutat no es redueix als intents d'absorció constant de què és objecte per part de tota mena de sistemes de territorialització i codificació; la ciutat és també - és sobretot - les energies sense forma que la recorren i que aprofiten la mínima oportunitat per reinstaurar un estat al mateix temps inicial i permanent de l'urbà com a desterritorialització $\mathrm{i}$ descodificació. És un camp de força, de tensions i distorsions, de desintegració del fix en una agitació interminable; és el viscós, filtrant-se per entre els intersticis d'allò que semblava sòlid i desmentint-ho.

\author{
MANUEL DELGADO \\ UNIVERSITAT DE BARCELONA
}




\section{REFERENNCIES}

DELGADO, Manuel, coord. Carrer, festa i revolta. Els usos simbòlics de la trama urbana. Barcelona: Departament de Cultura, Generalitat de Catalunya, 2003.

ENGELS, Friedrich. "Los bakuninistas en acción". Escritos en España. Barcelona: Planeta. 189-216

GOMA, Ricard, coord. Joventut, okupació $i$ polítiques públiques a Catalunya. Barcelona: Departament de Presidència, Generalitat de Catalunya, 2003.

FAVRE, Pierre. "Introduction. Manifester en France aujourd'hui". Dir. A. P. Favre. La manifestation. París: Presses de la Fondation National des Sciences Politiques, 1990. II-68.

HorTa, Gerard. De la mistica a les barricades. Introducció a l'espiritisme català del segle XIX en el context de l'ocultisme europeu. Barcelona: Proa, $200 r$.

- Cos i revolució. L'espiritisme català o les paradoxes de la modernitat. Barcelona: Edicions de $1984,2004$.

Kaplan, Temma. Ciudad roja, periodo azul. Movimientos sociales en la Barcelona de Picasso. Barcelona: Ediciones B, 2002.

LÓPEZ SANCHEZ, Pere. "1992, objectiu de tots? Ciutat-empresa i dualitat social a la Barcelona olímpica". Revista Catalana de Geografials (1991): $9 \mathrm{I}-99$.

- Un verano con mil julios y otras estaciones. Barcelona: de la Reforma Interior a la Revolución de Julio de igog. Barcelona: Siglo XXI, 1993.

MARTINEZ LOPEZ, Miguel. Okupaciones de vivendas y centros sociales. Augestión, contracultura y conflictos urbanos. Barcelona: Virus, 2002.

MiCHONNEAU, Stéphane. Barcelona: memòria $i$ identitat. Monuments, commemoracions i mites. Vic: Eumo, 2002.

NOYES, Dorothy. "Els performances de façana a la Catalunya moderna: ostentació, respecte, reivindicació, rebuig". Eds. J. Capdevila i A. García Larios. La festa a Catalunya. Barcelona: Publicacions de l'Abadia de Montserrat, 1997. 125-50.

Romero Maura, Joaquín. "La Rosa de Fuego". El obrerismo barcelonés de 189g a rgog. Madrid: Alianza, 1989 . 